\title{
A Newly-Developed Flow Diverter (FloWise) for Internal Carotid Artery Aneurysm: Results of a Pilot Clinical Study
}

\author{
Byung Moon Kim, MD, $P h D^{1}$, Keun Young Park, $M D^{2}$, Jae Whan Lee, $M D^{2}$, Joonho Chung, $M D^{2}$, \\ Dong Joon Kim, $\mathrm{MD}^{1}$, Dong Ik Kim, $M D^{3}$ \\ Departments of ${ }^{1}$ Radiology and ${ }^{2}$ Neurosurgery, Yonsei University College of Medicine, Severance Stroke Center, Severance Hospital, Seoul, Korea; \\ ${ }^{3}$ Department of Radiology, CHA Bundang Medical Center, CHA University, Seongnam, Korea
}

Objective: We report the results of a pilot clinical study that evaluated the safety and efficacy of a newly-developed, retrievable flow diverter (FloWise; Taewoong Medical) for the treatment of internal carotid artery (ICA) aneurysm.

Materials and Methods: A total of 10 patients were enrolled. Inclusion criteria were 1) unruptured aneurysm with a dome size of $\geq 8 \mathrm{~mm}$ and a neck size of $\geq 4 \mathrm{~mm}$ at the ICA, or 2) two or more unruptured aneurysms of any size able to be spanned by a single FloWise at the ICA. Co-primary effectiveness end points were technical success of FloWise placement, and a $50 \%$ or greater decrease in aneurysm volume at the 6-month follow-up angiogram. The primary safety end point was the new development of neurological deficits persisting for more than 1-month post-treatment.

Results: Ten patients harboring 14 ICA aneurysms (median diameter, $9.4 \mathrm{~mm}$; range, 2.3-31.0 mm) were enrolled between January 2016 and July 2017. FloWise placement was successful in all patients. There were no newly-developed neurological deficits during the 6-month clinical follow-up period. One patient did not receive follow-up imaging due to pregnancy. Nine patients with 12 aneurysms received a 6-month angiographic follow-up. Ten aneurysms (83.3\%) showed decreases in volume greater than $50 \%$ (mean volume decrease, $82.8 \pm 32.9 \%$ ), of which $8(66.7 \%, 95 \%$ confidence interval, $35.4-98.0 \%$ ) showed complete occlusion. One patient was retreated due to mass symptom aggravation.

Conclusions: In this pilot study, FloWise appeared to be safe and effective for ICA aneurysm treatment. A prospective multicenter study to validate the effectiveness and safety of FloWise would be worthwhile.

Keywords: Intracranial aneurysm; Flow diversion; New device

\section{INTRODUCTION}

Endovascular coiling is a standard therapy for intracranial aneurysm. Although it has been well documented that coiling is superior to clipping, one major drawback of coiling is a higher recurrence rate, especially in wideneck and/or large aneurysms (1,2). A flow diverter was developed to overcome this drawback. The concept of flow diversion therapy is that when a high metal density (low porosity) stent is placed across the aneurysm neck, it induces 1) a change in the direction of blood flow away from the target aneurysm sac toward the distal parent artery, and stasis of blood in the sac resulting in intraaneurysmal thrombosis, and 2) an acceleration of the neointima formation along the dense stent struts across the aneurysm neck. The combination of these effects can

Received July 3, 2018; accepted after revision October 17, 2018.

This study was supported by grants of the Korea Health Technology R\&D Project through the Korea Health Industry Development Institute (KHIDI), funded by the Ministry for Health \& Welfare, Republic of Korea (grant numbers HI08C2149 and HC151056).

Corresponding author: Byung Moon Kim, MD, PhD, Department of Radiology, Yonsei University College of Medicine, Severance Stroke Center, Severance Hospital, 50-1 Yonsei-ro, Seodaemun-gu, Seoul 03722, Korea.

- Tel: (822) 2228-7400 • Fax: (822) 393-3035• E-mail: bmoon21@hanmail.net

This is an Open Access article distributed under the terms of the Creative Commons Attribution Non-Commercial License (https:// creativecommons.org/licenses/by-nc/4.0) which permits unrestricted non-commercial use, distribution, and reproduction in any medium, provided the original work is properly cited. 
result in the exclusion of the aneurysm from circulation, and ultimately, aneurysm shrinkage. Since the introduction of flow diverters, a growing body of evidence has shown that they are more durable, and as a result, there has been a rapid increase in their use to treat aneurysms (3-6).

Recently, we reported that a newly-developed flow diverter (FloWise; Taewoong Medical, Seoul, Korea) was effective for aneurysm occlusion when evaluated in an elastase-induced rabbit aneurysm model (Fig. 1) (7). Here, we report the results of a single-center, prospective pilot study with a small number of human subjects. The aim of this pilot clinical study was to evaluate the safety and efficacy of the FloWise flow diverter.

\section{MATERIALS AND METHODS}

This study was approved by the Institutional Review Board, and written informed consent was obtained from every patient before enrollment in the study. Verbal explanations were given to both the patient, and at least one first-degree relative twice, and written informed consent was obtained by the primary investigator.

This study was conducted as a single-center, pilot clinical study to evaluate the safety and efficacy of FloWise in a small population $(n=10)$ prior to launching a large, multicenter prospective study. Inclusion criteria were as follows: 1) 18-75 years of age, 2) pre-treatment modified Rankin scale score (mRS) of $0-2,3)$ unruptured internal carotid artery (ICA) aneurysm with a dome diameter $\geq 8$ $\mathrm{mm}$ and a neck diameter $\geq 4 \mathrm{~mm}$, or 2 or more unruptured ICA aneurysms able to be spanned by a single FloWise, and 4) written informed consent. Exclusion criteria were as follows: 1) currently pregnant, 2) intracranial hemorrhage within the last 30 days, 3 ) untreated aneurysm that had ruptured within the last 30 days, 4) any contraindication for antiplatelet medication use, 5) major surgery within 30 days of the treatment, 6 ) a platelet count of less than $100000,7)$ untreated cancer or immunocompromising disease, 8) serum creatinine levels of more than $2.5 \mathrm{mg} / \mathrm{dL}$, 9) a previously inserted stent in the parent artery harboring the target aneurysm, 10) nitinol allergy, 11) uncontrolled hypersensitivity to iodine contrast material, 12) active infection, and 13) a life expectancy of less than 5 years. Ten patients (all women; median age, 56 years; age range, 28-72 years) harboring 14 ICA aneurysms (median size, 9.4 $\mathrm{mm}$; range, 2.3-31.0 mm; median neck diameter, $7.1 \mathrm{~mm}$; neck diameter range, 2.0-10.2 mm) were enrolled between
January 2016 and July 2017.

\section{Antiplatelet Medication}

All enrolled patients received dual antiplatelet medication (100 mg aspirin with $75 \mathrm{mg}$ clopidogrel) for at least 5 days before treatment. An antiplatelet drug resistance test was obtained 1 day before treatment. If the antiplatelet resistance test was positive, an antiplatelet drug with a different mechanism of action was added. After completion of the treatment, dual antiplatelet medication was continued for 6 months, and then replaced by aspirin monotherapy.

\section{The Flowise Flow Diverter}

The specifications of the FloWise stent and the in vivo experimental results in a rabbit aneurysm model have been previously reported (7). Briefly, the FloWise flow diverter stent is composed of a braiding of 48 strands of 0.0012-inch nitinol and platinum wires. These 48 strands are braided and heat-treated in the expanded configuration. After deployment from the delivery system, the FloWise expands to cover the neck of the aneurysm, forming a high-coverage mesh of approximately $33-41 \%$ by area, with a radioopacity similar to that of the Pipeline Flex (Medtronic, CA, USA) embolization device (Fig. 1A). The FloWise is attached to a flexible delivery wire, which has radio-opaque end markers, and is packaged in an introducer sheath. The distal tip of the delivery wire is pre-shaped to a J shape (Fig. 1B). The stent-contact portion of the delivery wire is coated with silicon so that it grips the FloWise, which allows for re-sheathing at any point prior to $70 \%$ deployment (Fig. 1C). This packaged device can be loaded into standard microcatheters with at least a 0.027 -inch inner diameter. It is pushed through the microcatheter and deployed by a combination of microcatheter withdrawal and forward pressure on the delivery wire. The FloWise undergoes approximately $38 \%$ shortening when deployed completely. The FloWise is available in $3.0,3.5,4.0,4.5$, and $5.0 \mathrm{~mm}$ in diameter, and 20, 25, 30, 35, and $40 \mathrm{~mm}$ in length.

\section{Implantation of the Flowise Flow Diverter}

All patients were treated under general anesthesia. After placement of a 6-Fr shuttle guide sheath (Shuttle, Cook, CA, USA) in the relevant ICA, a 5-Fr intermediate catheter (Sofia; Microvention-Terumo, Tustin, CA, USA) was advanced through the shuttle sheath up the petrous or cavernous segment of the ICA as far as possible. A 0.027- 

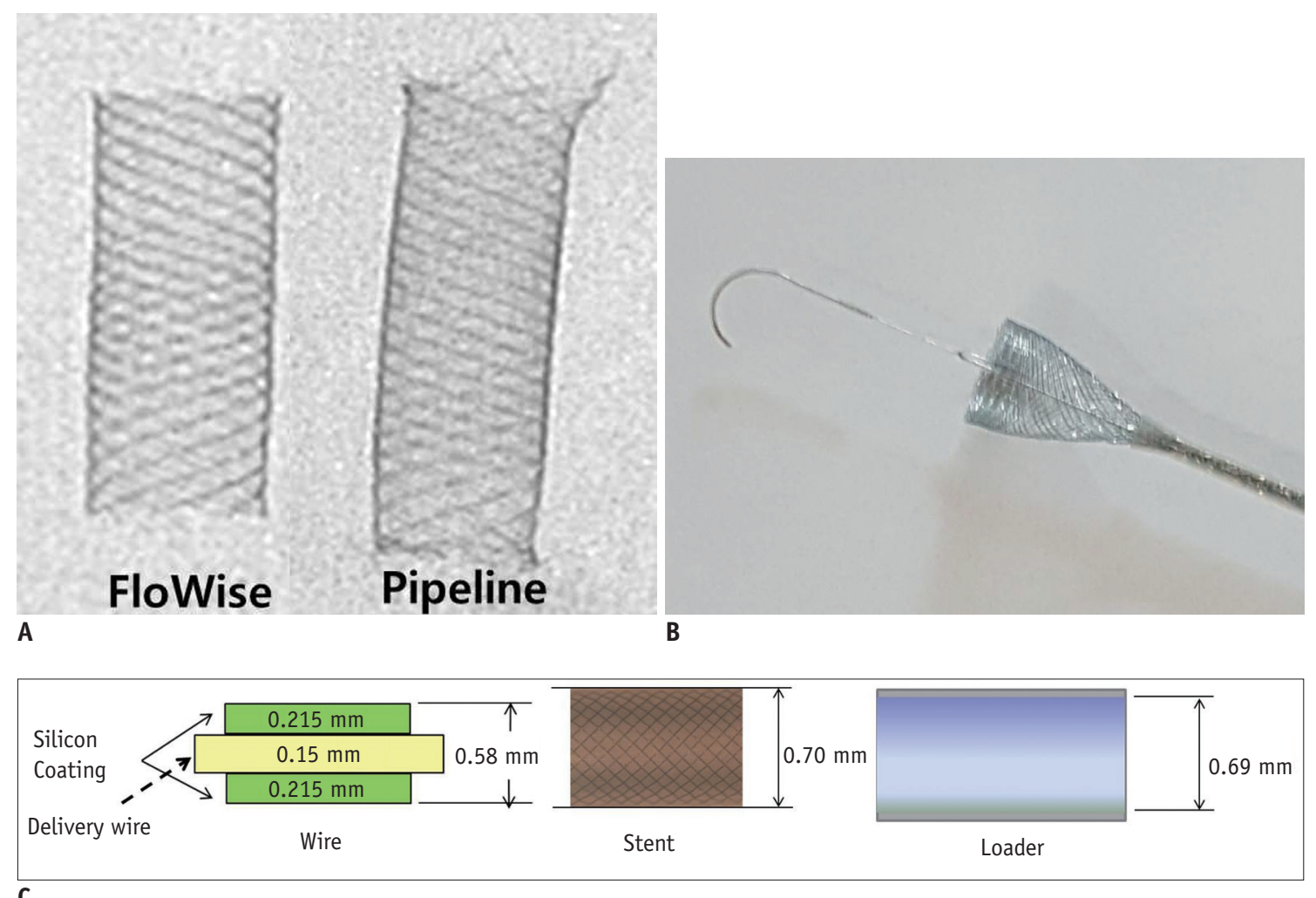

Fig. 1. FloWise (Taewoong Medical) flow diverter.

A. Spot image of FloWise and Pipeline Flex (Medtronic) flow diverters. B. Image of partially deployed FloWise stent. Note distal tip of stentloading delivery wire is pre-shaped in J configuration. C. Schematic drawing of FloWise design.

inch microcatheter was navigated up to the ipsilateral middle cerebral artery M2 or M3 segment using a 0.014inch microwire. Then, a FloWise stent that matched the largest diameter of the parent artery was introduced into the microcatheter and deployed, completely spanning the aneurysm neck. After deployment of the FloWise, followup angiograms were obtained at least two times each for 10 minutes. If enough flow diversion (shift of inflow zone from aneurysm distal neck to proximal neck and disruption of inflow jet), as judged by an experienced operator, was not seen after the first FloWise had been successfully implanted, an additional FloWise was inserted in an overlapping manner. If an acute in-stent thrombosis was detected, glycoprotein IIb/IIIa inhibitor (tirofiban, 0.5-1.0 $\mathrm{mg}$ ) was intra-arterially administered and maintained for 12 hours after completion of the procedure.

\section{Clinical and Imaging Follow Up}

Outpatient based clinical follow-up was scheduled at one and three months post procedure. A computed tomography (CT) angiogram was obtained at the 3-month follow-up. The patient was then scheduled for readmission at 6 months \pm 2 weeks for follow-up angiography. A data safety monitoring board (DSMB) was organized in order to maintain patient safety. The DSMB was independently composed of two physicians who were not working in the study hospital. During the clinical follow-up, telephone and e-mail contact with a clinical research assistant was possible at any time. If the patient complained of any symptom potentially related to the treatment, it was reported to the primary investigator as soon as possible. Complaints were recorded and the DSMB evaluated whether or not they were related to the treatment. Retreatment was planned in the event that, at the 6-month follow-up angiogram, the target aneurysm was found to be enlarged, causing any new neurological symptoms.

\section{Primary and Secondary Endpoints}

Co-primary endpoints included the rate of technical success, and a $50 \%$ or greater decrease in aneurysm sac volume at the 6-month follow-up angiogram. Technical success was defined as whether FloWise completely covered the neck of the target aneurysm. The secondary endpoint was the rate of complete occlusion at the 6-month follow- 
up angiogram.

The primary safety endpoint was the development of a new neurological morbidity (defined by an mRS score $\geq$ 3) that persisted for more than 1 month post-treatment. Secondary safety endpoints were the development of new symptomatic ipsilateral ischemic stroke $\geq 5$ on the National Institute of Health Stroke Scale, and an in-stent stenosis of more than $50 \%$ at the 6 -month follow-up angiogram.

\section{Statistical Analysis}

Statistical analysis was performed using IBM SPSS version 20 (IBM Corp., Armonk, NY, USA). Continuous variables are presented as the mean \pm standard deviation, and categorical variables as numbers and percentages. The rates of primary and secondary end points were assessed at 6 months and presented as numbers and percentages.

\section{RESULTS}

FloWise placement was successful in all 10 patients. Eight patients were treated with a single FloWise stent, one patient was treated with two, and one patient was treated with three overlapping FloWise stents in order to obtain more flow diversion. Table 1 summarizes patient and aneurysm characteristics and 6-month follow-up results.

No new neurological deficits developed during the 6-month clinical follow-up period. Nine patients with 12 aneurysms received 6 months of angiographic follow- up. One patient did not receive follow-up imaging due to pregnancy. One patient was retreated with Pipeline Flex due to lack of change in aneurysm volume, and progressive mass symptom aggravation. The patient's symptoms resolved completely after 1 month of retreatment and resulted in complete occlusion of the aneurysm 6 months posttreatment. Ten aneurysms ( $83.3 \%$ ) showed a $50 \%$ or more decrease in volume (mean volume decrease, $82.8 \pm 32.9 \%$ ) of which 8 (66.7\%, 95\% confidence interval, 35.4-98.0\%) showed complete occlusion (Fig. 2). One patient, who had three overlapping FloWise stents, showed asymptomatic instent stenosis $\geq 50 \%$ (Fig. 3). At 12 months, 10 aneurysms $(83.3 \%)$ showed complete occlusion.

\section{DISCUSSION}

In this pilot prospective clinical study, FloWise showed 1) no treatment-related complications, 2) an aneurysm volume decrease of $50 \%$ or more in $83.3 \%$ of the treated aneurysms at 6 months, and 3) complete occlusion of $66.7 \%$, and $83.3 \%$ of target aneurysms at 6 months and 12 months, respectively.

Endovascular treatment is one of the standard treatments for intracranial aneurysms and has been shown to be superior to clipping in the majority of reports $(1,2,8)$. However, conventional endovascular coil embolization yields low complete occlusion rates and high recurrence rates, especially in wide-necked, large, and giant aneurysms

Table 1. Patients and Aneurysm Characteristics, and 6-Month Follow-Up Results

\begin{tabular}{|c|c|c|c|c|c|c|c|c|}
\hline Pt & Sex/Age & Location & $\begin{array}{l}\text { Dome Size } \\
(\mathrm{mm})\end{array}$ & $\begin{array}{l}\text { Neck Size } \\
(\mathrm{mm})\end{array}$ & $\begin{array}{l}\text { Aneurysm Occlusion } \\
\text { at } 6 \text { Months }\end{array}$ & $\begin{array}{l}\text { Volume Decrease } \\
\text { at } 6 \text { Months }(\%)\end{array}$ & $\mathrm{mRS}$ & Comments \\
\hline 1 & $F / 56$ & Left ICA paraclinoid & 8.3 & 5.5 & Complete & 100 & 0 & \\
\hline 2 & $F / 52$ & Left ICA paraclinoid & 17.8 & 8.9 & No change & 0 & 0 & $\begin{array}{l}\text { Retreatment (Pipeline } \\
\text { Flex*) at } 6 \text { months }\end{array}$ \\
\hline 3 & $F / 42$ & Right ICA paraclinoid & 11.0 & 8.15 & Neck remnant & 85 & 0 & \\
\hline 4 & $F / 62$ & Right ICA paraclinoid & 9.4 & 8.83 & Complete & 100 & 0 & \\
\hline 5 & $\mathrm{~F} / 59$ & Left ICA paraclinoid & 8.2 & 8.4 & Incomplete & 33 & 0 & \\
\hline \multirow{2}{*}{6} & \multirow{2}{*}{$F / 28$} & Right ICA ophthalmic & 4.5 & 4.2 & NA & NA & 0 & \multirow{2}{*}{$\begin{array}{l}\text { Lost to imaging follow- } \\
\text { up due to pregnancy }\end{array}$} \\
\hline & & Right ICA paraclinoid & 4.0 & 4.0 & NA & NA & 0 & \\
\hline \multirow{2}{*}{7} & \multirow{2}{*}{$\mathrm{F} / 72$} & Left ICA paraclinoid & 11.0 & 6.7 & Neck remnant & 100 & 0 & \\
\hline & & Left ICA ophthalmic & 2.3 & 2.0 & Complete & 100 & 0 & \\
\hline 8 & $F / 52$ & Right ICA paraclinoid & 15.4 & 5.5 & Complete & 100 & 0 & \\
\hline \multirow{2}{*}{9} & \multirow{2}{*}{$F / 57$} & Right ICA paraclinoid & 15.3 & 10.6 & Partial occlusion & 73 & 0 & \\
\hline & & Right ICA paraclinoid & 31.0 & 7.5 & Complete & 100 & 0 & \\
\hline \multirow{2}{*}{10} & \multirow{2}{*}{$F / 67$} & Left ICA paraclinoid & 2.5 & 2.0 & Complete & 100 & 0 & \\
\hline & & Left ICA paraclinoid & 2.0 & 2.0 & Complete & 100 & 0 & \\
\hline
\end{tabular}

*Pipeline Flex, Medtronic. $\mathrm{F}=$ female, $\mathrm{ICA}=$ internal carotid artery, $\mathrm{mRS}=$ modified Rankin scale score, $\mathrm{NA}=$ not applicable, $\mathrm{Pt}=$ number of patient 


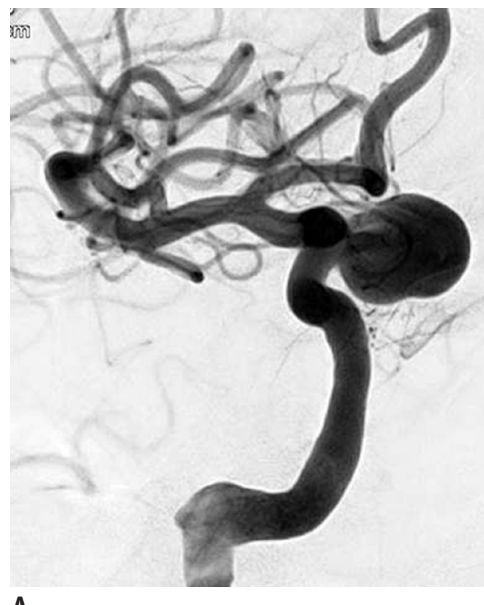

A

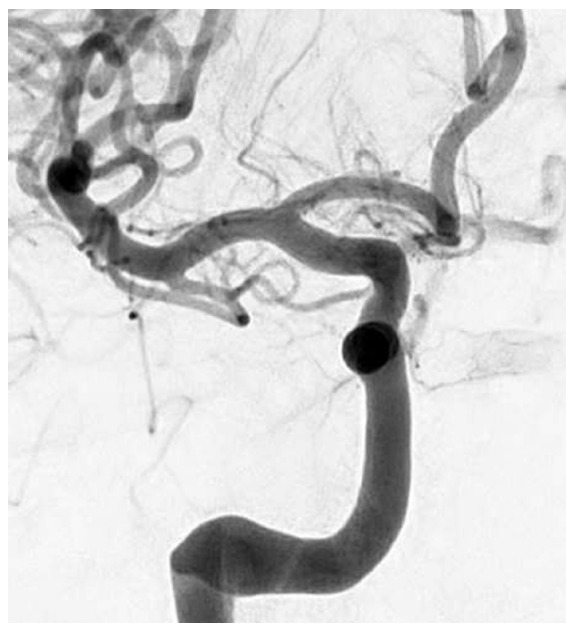

D

Fig. 2. 52-year-old woman presented with large aneurysm at right ICA paraclinoid segment.

A. Right carotid angiogram shows 15.4-mm-sized aneurysm at ICA paraclinoid segment. B. Spot image during FloWise deployment. Note that distal tip of FloWise loading delivery wire is pre-shaped in J configuration (arrow). C. Spot image 10 minutes after FloWise deployment shows that contrast materials still remain in aneurysm sac. D. 6-month follow-up angiogram shows complete occlusion of aneurysm. E. Initial T2weighted MR image shows large aneurysm (arrow) at intradural portion of right ICA. F. 12-month follow-up T2-weighted MR image shows disappearance of aneurysm. ICA $=$ internal carotid artery, $M R=$ magnetic resonance

(8-10). With advanced techniques, such as a multi-catheter, balloon, stent assistance, or a combination of these techniques, most difficult aneurysms can be treated (1116). However, advanced techniques require more technical demands, and, as a result, a number of complex or fusiform aneurysms remain uncoilable (3). A treatment with multiple overlapping stents was initially developed for flow diversion therapy in dissecting, blister-like, or fusiform aneurysms and had shown promising results (17-25). In addition, in vitro experimental studies showed a high probability of success when implementing flow diversion therapy for aneurysm treatment $(26,27)$. Based on the results of clinical and experimental studies, flow diverter stents have been developed for the treatment of wide-necked, large, and giant aneurysms, which are difficult to treat with coiling $(3,28)$. A growing body of evidence is available on the effectiveness of flow diverters for treating various types of aneurysms (3-6). There have been several commercially available flow diverters; Pipeline Flex, SILK (Balt Extrusion, Montmorency, France), Surpass Streamline (Stryker Neurovascular, Fremont, CA, USA), FRED (MicroventionTerumo). The characteristics of these flow diverters are summarized in Table 2.

Until recently, there were several flow diverter types commercially available in Korea, and a multicenter experience was reported (29). However, these flow diverters were quite expensive and required technical expertise. As a result, aneurysm treatment with commercially available 


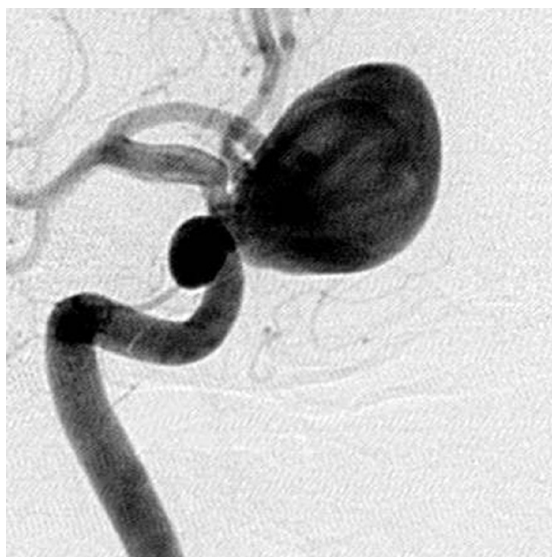

A

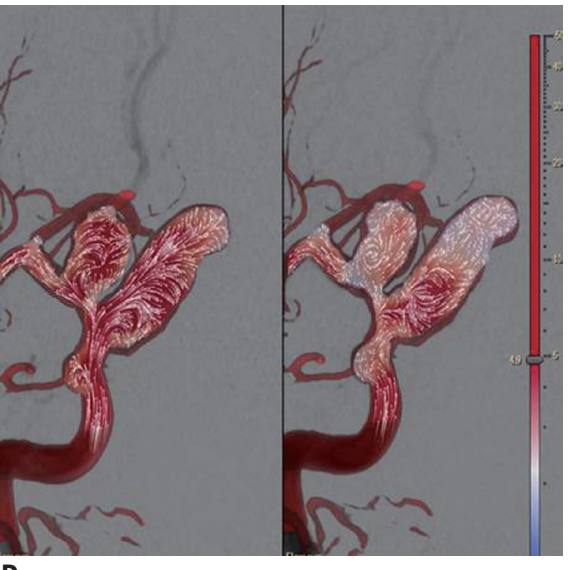

D

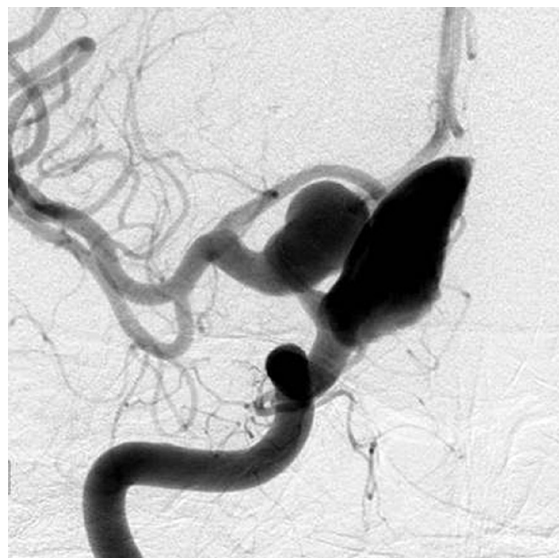

B

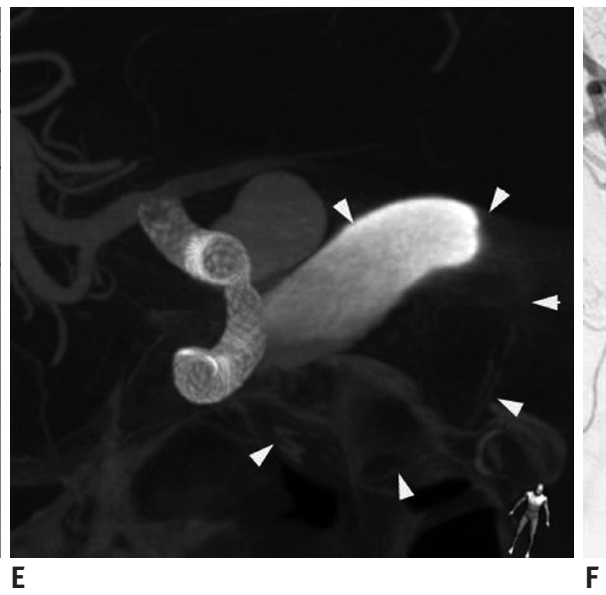

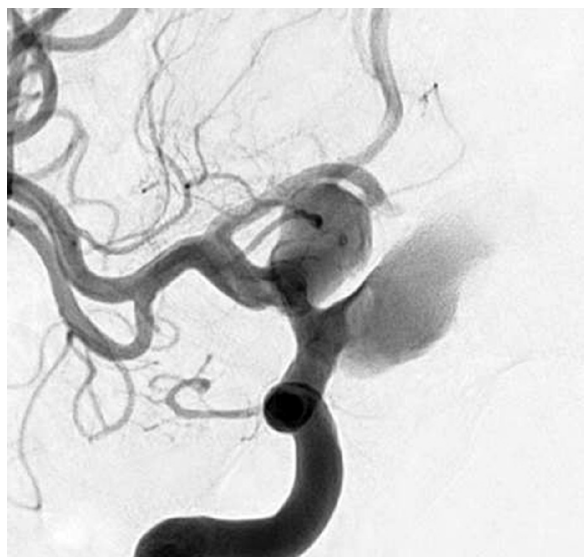

C

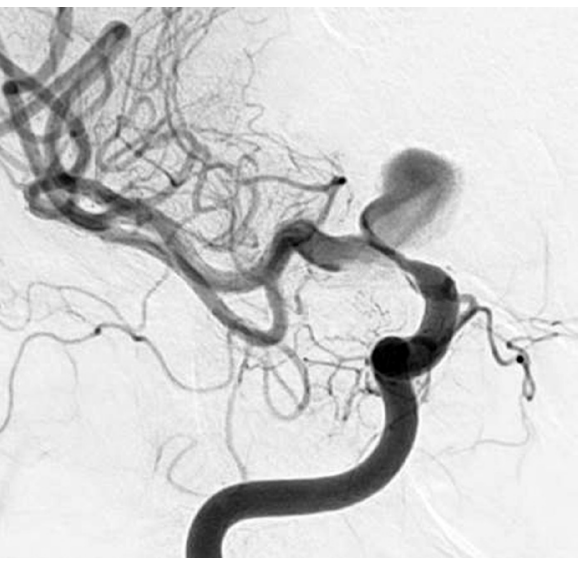

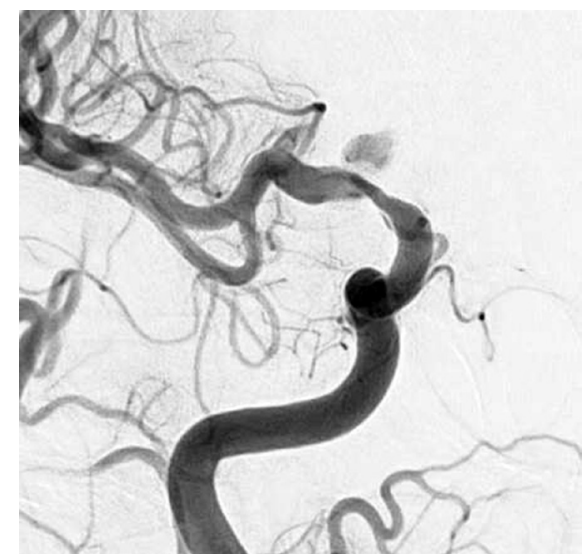

G

Fig. 3. 57-year-old woman presenting with recurrent aneurysms 10 years after wrapping of giant aneurysm at right ICA paraclinoid segment.

A. Initial right carotid angiogram shows giant aneurysm. B. Right carotid angiogram 10 years after initial treatment shows large aneurysm at supraclinoid segment and partially thrombosed giant aneurysm at paraclinoid segment. C. Right carotid angiogram just after three FloWise stent placements. D. Aneurysm flow before (left) and after (right) shows marked flow diversion effect. Note inflow zone is shifted from distal to proximal neck and inflow jets do not reach aneurysm dome. Arrows in the sac and their magnitude indicate flow direction and velocity, respectively. E. Flat-panel computed tomography image immediately after treatment with three overlapping FloWise stents. Arrowheads indicate outline of partially thrombosed giant aneurysm at paraclinoid segment of right ICA. F. 6-month follow-up angiogram after treatment with three FloWise stents shows complete occlusion of giant aneurysm at paraclinoid segment and decrease in size of large aneurysm at supraclinoid segment. Degree of stenosis between two aneurysms was aggravated, but patient remained asymptomatic. G. 12-month follow-up angiogram shows greater decrease in size of aneurysm at supraclinoid segment and slight improvement of stenosis. 
Table 2. Characteristics of Other Commercially Available Flow Diverters

\begin{tabular}{|c|c|c|c|c|}
\hline Flow Diverter* & Diameter/Length $(\mathrm{mm})$ & Material & Number of Strands & Resheathability \\
\hline Pipeline Flex & $2.5-5 / 10-35$ & $\begin{array}{l}\text { Cobalt chrome, } \\
\text { platinum-tungsten }\end{array}$ & 48 & Up to $90 \%$ \\
\hline Surpass Streamline & $2-5 / 12-50$ & $\begin{array}{l}\text { Cobalt chrome, } \\
\text { platinum-tungsten }\end{array}$ & $48(2 \mathrm{~mm}), 72(3-4 \mathrm{~mm}), 96(5 \mathrm{~mm})$ & $\begin{array}{l}\text { Up to } 11 \mathrm{~mm} \text { between } \\
\text { catheter tip and pusher }\end{array}$ \\
\hline SILK & $2-5 / 15-40$ & Nitinol, platinum & 48 & Up to $90 \%$ \\
\hline FRED & $3.5-5.5 / 7-56$ & Nitinol, tantalum & Dual layer; 48 (inner), 16 (outer) & Up to $80 \%$ \\
\hline
\end{tabular}

*Pipeline Flex, Medtronic; Surpass Streamline, Stryker Neurovascular; SILK, Balt Extrusion: FRED, Microvention-Terumo

flow diverters is very limited in Korea and has resulted in considerable one-month mortality rates (30).

We developed a new flow diverter that is easy to use and resheathable. It has a metal density of approximately $33-41 \%$, depending on the relationship between the parent vessel and stent diameter, which is comparable to other commercially available flow diverters (31). This pilot study was conducted to preliminarily evaluate the safety and effectiveness of the FloWise flow diverter before a prospective multicenter study. FloWise placement was successful in all patients, and there were no newlydeveloped neurological symptoms during the 6-month follow-up period. However, it has been reported in the literature that other commercially available flow diverters have shown combined major morbidity and neurological mortality rates of $5.6-7.7 \%(4,5)$. Due to the small sample size of this pilot study, it cannot be assumed that the Flowise flow diverter is safer than other commercially available flow diverters. One explanation for the absence of complication in this pilot study is that all procedures were done by a single operator who had extensive experience in commercially available flow diverters. Given that implantation of a flow diverter stent requires considerable technical expertise, placement by an experienced operator might be helpful to avoid periprocedural complications. Additionally, in cases that an operator judged flow diversion to be insufficient after implantation of the first FloWise, additional devices were overlapped until flow diversion appeared to be sufficient. In the authors' opinion, this may help to avoid delayed complications, such as aneurysm rupture. Complete occlusion was observed in $66.7 \%$ and $83.3 \%$ of target aneurysms at 6 months and 12 months, respectively, after FloWise implantation. These rates are comparable with the rates reported in the literature (55.793.3\%) (32). Although the sample size was small, the safety and effectiveness of FloWise did not appear to be inferior to the safety and effectiveness of commercially available flow diverters. If FloWise's safety and effectiveness is validated in a larger population, FloWise could be an additional tool for flow diversion therapy in intracranial aneurysms.

In conclusion, FloWise appears to be a safe and effective treatment for unruptured ICA aneurysms. A prospective multicenter study to validate the safety and effectiveness of the FloWise stent would be worthwhile.

\section{Conflicts of Interest}

The authors have no financial conflicts of interest.

ORCID

Byung Moon Kim

https://orcid.org/0000-0001-8593-6841

\section{REFERENCES}

1. Molyneux AJ, Kerr RS, Birks J, Ramzi N, Yarnold J, Sneade $M$, et al.; ISAT Collaborators. Risk of recurrent subarachnoid haemorrhage, death, or dependence and standardised mortality ratios after clipping or coiling of an intracranial aneurysm in the International Subarachnoid Aneurysm Trial (ISAT): long-term follow-up. Lancet Neurol 2009;8:427-433

2. Raymond J, Guilbert F, Weill A, Georganos SA, Juravsky $L$, Lambert $A$, et al. Long-term angiographic recurrences after selective endovascular treatment of aneurysms with detachable coils. Stroke 2003;34:1398-1403

3. Becske T, Kallmes DF, Saatci I, McDougall CG, Szikora I, Lanzino G, et al. Pipeline for uncoilable or failed aneurysms: results from a multicenter clinical trial. Radiology 2013;267:858-868

4. Zhou G, Su M, Zhu YQ, Li MH. Efficacy of flow-diverting devices for cerebral aneurysms: a systematic review and metaanalysis. World Neurosurg 2016;85:252-262

5. Kallmes DF, Brinjikji W, Cekirge S, Fiorella D, Hanel RA, Jabbour $\mathrm{P}$, et al. Safety and efficacy of the Pipeline embolization device for treatment of intracranial aneurysms: a pooled analysis of 3 large studies. J Neurosurg 2017;127:775780

6. Zhang $Y$, Huang $Q H$, Fang $Y$, Yang $P, X u Y$, Hong B, et al. A 
novel flow diverter (Tubridge) for the treatment of recurrent aneurysms: a single-center experience. Korean J Radiol 2017;18:852-859

7. Kim BM, Kim DJ, Kim DI. A new flow-diverter (the FloWise): in-vivo evaluation in an elastase-Induced rabbit aneurysm model. Korean J Radiol 2016;17:151-158

8. Molyneux AJ, Kerr RS, Yu LM, Clarke M, Sneade M, Yarnold JA, et al. International Subarachnoid Aneurysm Trial (ISAT) of neurosurgical clipping versus endovascular coiling in 2143 patients with ruptured intracranial aneurysms: a randomised comparison of effects on survival, dependency, seizures, rebleeding, subgroups, and aneurysm occlusion. Lancet 2005;366:809-817

9. Campi A, Ramzi N, Molyneux AJ, Summers PE, Kerr RS, Sneade $M$, et al. Retreatment of ruptured cerebral aneurysms in patients randomized by coiling or clipping in the International Subarachnoid Aneurysm Trial (ISAT). Stroke 2007;38:1538-1544

10. Darsaut TE, Darsaut NM, Chang SD, Silverberg GD, Shuer LM, Tian $\mathrm{L}$, et al. Predictors of clinical and angiographic outcome after surgical or endovascular therapy of very large and giant intracranial aneurysms. Neurosurgery 2011;68:903-915; discussion 915

11. Kim BM, Park SI, Kim DJ, Kim DI, Suh SH, Kwon TH, et al. Endovascular coil embolization of aneurysms with a branch incorporated into the sac. AJNR Am J Neuroradiol 2010;31:145-151

12. Rho MH, Kim BM, Suh SH, Kim DJ, Kim DI. Initial experience with the new double-lumen scepter balloon catheter for treatment of wide-necked aneurysms. Korean $\mathrm{J}$ Radiol 2013; 14:832-840

13. Ihn YK, Kim BM, Suh SH, Kim DJ, Kim DI. Coil-protected embolization technique for a branch-incorporated aneurysm. Korean J Radiol 2013;14:329-336

14. Park KY, Kim BM, Kim DJ. Comparison between balloonassisted and stent-assisted technique for treatment of unruptured internal carotid artery aneurysms. Neurointervention 2016;11:99-104

15. Jeon P, Kim BM, Kim DJ, Kim DI, Park KY. Y-configuration double-stent-assisted coiling using two closed-cell stents for wide-neck basilar tip aneurysms. Acta Neurochir (Wien) 2014;156:1677-1686

16. Kim BM, Kim DJ, Kim DI. Stent application for the treatment of cerebral aneurysms. Neurointervention 2011;6:53-70

17. Benndorf G, Herbon U, Sollmann WP, Campi A. Treatment of a ruptured dissecting vertebral artery aneurysm with double stent placement: case report. AJNR Am J Neuroradiol 2001;22:1844-1848

18. Fiorella D, Albuquerque FC, Deshmukh VR, Woo HH, Rasmussen PA, Masaryk TJ, et al. Endovascular reconstruction with the Neuroform stent as monotherapy for the treatment of uncoilable intradural pseudoaneurysms. Neurosurgery 2006;59:291-300; discussion 291-300

19. Park SI, Kim BM, Kim DI, Shin YS, Suh SH, Chung EC, et al.
Clinical and angiographic follow-up of stent-only therapy for acute intracranial vertebrobasilar dissecting aneurysms. AJNR Am J Neuroradiol 2009;30:1351-1356

20. Suh SH, Kim BM, Park SI, Kim DI, Shin YS, Kim EJ, et al. Stent-assisted coil embolization followed by a stent-withina-stent technique for ruptured dissecting aneurysms of the intracranial vertebrobasilar artery. Clinical article. J Neurosurg 2009;111:48-52

21. Kim BM, Suh SH, Park SI, Shin YS, Chung EC, Lee MH, et al. Management and clinical outcome of acute basilar artery dissection. AJNR Am J Neuroradiol 2008;29:1937-1941

22. Kim BM, Chung EC, Park SI, Choi CS, Won YS. Treatment of blood blister-like aneurysm of the internal carotid artery with stent-assisted coil embolization followed by stent-withina-stent technique. Case report. J Neurosurg 2007;107:12111213

23. Lee BH, Kim BM, Park MS, Park SI, Chung EC, Suh SH, et al. Reconstructive endovascular treatment of ruptured blood blister-like aneurysms of the internal carotid artery. $J$ Neurosurg 2009;110:431-436

24. Lim YC, Kim BM, Suh SH, Jeon P, Kim SH, Ihn YK, et al. Reconstructive treatment of ruptured blood blister-like aneurysms with stent and coil. Neurosurgery 2013;73:480-488

25. Jeon P, Kim BM, Kim DI, Park SI, Kim KH, Kim DJ, et al. Reconstructive endovascular treatment of fusiform or ultrawide-neck circumferential aneurysms with multiple overlapping enterprise stents and coiling. AJNR Am J Neuroradiol 2012;33:965-971

26. Cantón G, Levy DI, Lasheras JC, Nelson PK. Flow changes caused by the sequential placement of stents across the neck of sidewall cerebral aneurysms. J Neurosurg 2005;103:891-902

27. Kim M, Levy EI, Meng H, Hopkins LN. Quantification of hemodynamic changes induced by virtual placement of multiple stents across a wide-necked basilar trunk aneurysm. Neurosurgery 2007;61:1305-1312; discussion 1312-1313

28. Kallmes DF, Ding YH, Dai D, Kadirvel R, Lewis DA, Cloft HJ. A second-generation, endoluminal, flow-disrupting device for treatment of saccular aneurysms. AJNR Am J Neuroradiol 2009;30:1153-1158

29. Kim BM, Shin YS, Baik MW, Lee DH, Jeon P, Baik SK, et al. Pipeline embolization device for large/giant or fusiform aneurysms: an initial multi-center experience in Korea. Neurointervention 2016;11:10-17

30. Kim T, Kwon OK, Lee H, Cho MJ, Jeong HJ, Ban SP. Nationwide mortality data after flow-diverting stent implantation in Korea. J Korean Neurosurg Soc 2018;61:219-223

31. Rajah G, Narayanan S, Rangel-Castilla L. Update on flow diverters for the endovascular management of cerebral aneurysms. Neurosurg Focus 2017;42:E2

32. Liu JM, Zhou Y, Li Y, Li T, Leng B, Zhang P, et al.; PARAT investigators. Parent artery reconstruction for large or giant cerebral aneurysms using the tubridge flow diverter: a multicenter, randomized, controlled clinical trial (PARAT). AJNR Am J Neuroradiol 2018;39:807-816 